This is a pre-publication draft of Leaver, T. (2019). Posthumous Performance and Digital

Resurrection: From Science Fiction to Startups. In T. Kohn, M. Gibbs, B. Nansen, \& L. van Ryn (Eds.),

Residues of Death: Disposal Refigured. London \& New York: Routledge.

\title{
Posthumous Performance and Digital Resurrection: From Science Fiction to Startups
}

Tama Leaver, Internet Studies, Curtin University

Technology enabling resurrection and reanimation of the dead has long been a theme in popular culture, and in science fiction (SF) in particular. Mary Shelley's Frankenstein (1823), generally considered the beginning of SF as a genre (Freedman, 2000), tells the tale of a scientist who harnesses technology and electricity to reanimate an entity stitched together from the remains of the recent dead. However, it is telling that Victor Frankenstein is now generally considered a metaphor for the arrogance of scientists who fail to consider the harmful potential of their work. While rarely as dramatic as stories of resurrection, Tony Walter (Walter, 2015) has convincingly argued that for thousands of years every communication technology, from etching in stone and cave paintings onward, has been used to communicate with the dead in some fashion. It comes as no surprise, then, that technology start-ups and entrepreneurs are attempting to harness digital technologies, social media, and networked communication not just to speak to the dead but also to use their digital residues to seemingly offer both resurrection and immortality.

This chapter examines the promotional discourse deployed by three of these futuristic start-up companies - LivesOn (LivesOn, 2013), Eterni.me ("Eterni.me - Virtual Immortality," 2016) and Humai (Humai, 2016) - and compares these with several notable SF texts which explore the underlying presumptions and broader cultural and social ramifications of these companies succeeding in achieving digital resurrection. The episode 'Be Right Back' of the dystopian television series Black Mirror (Harris, 2013) imagines a world where someone could be reconstituted from the detailed record of their lives left behind across various social media accounts, but with clear echoes of Frankenstein. The series returns to these themes in a more endearing fashion in the upbeat 'San Junipero' (Harris, 2016) which features a digital afterlife fashioned after the nineteen eighties. Australian hard SF author and computer scientist Greg Egan also explores this terrain in great detail; his short story 'Learning to be Me' (Egan, 1995) and novel Permutation City (Egan, 1994) reveal many of the philosophical presumptions and potential outcomes of a digitised afterlife (Leaver, 2004). In comparing these technology companies and SF texts, this chapter operates on two levels: the first, being to ask what presumptions are being made about contemporary personhood, culture and death; and secondly, mapping what future issues might the success of these start-ups actually provoke. 


\section{Black Mirror}

The episode 'Be Right Back' written by Charlie Brooker in the UK television series Black Mirror (Harris, 2013) features a young couple, Martha (Hayley Atwell) and Ash (Domhnall Gleeson). Ash is a heavy social media user, with a significant web presence. After Ash unexpectedly dies, a griefstricken and pregnant Martha accepts the invitation from a friend to use an online service which allows you to talk to (an approximation) of the dead. The (unnamed) company mine all of Ash's online residues in order to algorithmically mimic him to the extent that Martha is able to interact with Ash in textual form, using a messenger-like interface. As Martha moves past her initial unease with this partially reanimated Ash, she wants to talk, not just type, and allows the software access to all of her personal files of Ash - all of their recorded videos, private photographs and other documented moments. This allows the software to 'learn' how Ash sounds, and soon 'he' is able to speak with her in real-time on the telephone. The dystopian turn comes when Martha pays for the final level, and a realistic looking physical version of Ash is created, and the digital Ash is embodied and 'he' can once again walk around and physically interact with Martha. There are clear limits to 'his' knowledge and ability to understand; 'his' memory is partial and imprecise since the new Ash only has access to the moments that were digitally recorded. In the end, the differences end up being too much for Martha who initially wants Ash gone, but concedes to letting 'him' live in the attic, but the episode implies this entails long periods without human contact, and clearly positions the new entity as something quite different to the organic human on which he was based.

The initial wonder at Ash's seeming resurrection in 'Be Right Back' is slowly but dramatically replaced with Martha's increasing sense that Ash shouldn't be there. When the reanimated Ash takes physical form, Martha notes he looks a little too good; the new Ash notes that he's built from social media traces and that people (Ash included, clearly) tend to document and share the very best that they look. Indeed, this scene evokes Erving Goffman's (Goffman, 1959) notion that in social situations people put on various faces or performances which are driven by context. Social media is one (or more) of those spaces, begging the question which facets of Ash the recreation has been able to access and mimic. Ash's limitation become more apparent - 'he' doesn't need to sleep or eat, and doesn't make breathing noises at night - and his 'memories' are partial and fragmented. Ash is an evocation of the "uncanny valley" - a notion from robotics (Mori, 2012) and later films studies (Monnet, 2004; Ravetto-Biagioli, 2016) that argues that the closer technology comes to human form, the louder and more intrusive the small imperfections and errors become. Looking at the new Ash, Martha expects ' $h i m$ ' to be like the original, yet every deviation is a stark reminder that Ash isn't Ash. Finally, Martha resolves to have the new Ash suicide, but when she explains the 'real' Ash would beg her not to, the new Ash mimics that action, too. When the episode ends on Ash 'living' in the attic, some eight years later, occasionally visited by Martha and (real) Ash's daughter, the scene is deeply unsettling. The way it is shot suggests that Ash may simply wait there, inactive, possibly unaging, for the rest of time. There is a stark juxtaposition here with two earlier scenes; the first, before Ash's death, where he and Martha are looking at a photograph and Martha thinks it looks sweet, before Ash explains the photo's context which was must bleaker; the second, just after Ash's funeral, shows Martha exploring boxes of photos. The implication of the final scene, then, is both that the Ash recreation is now those photos, living in the attic, but the 'story' of Ash that he embodies is likely partial and incorrect in a range of different ways. Ash is, in many respects, a social media version of Frankenstein's monster, not violent, but nevertheless disrupting the everyday norms and boundaries of life. 
Notably, the Black Mirror series revisited the theme of digital life after death in the third season, the first on the streaming service Netflix. In the episode 'San Junipero' (Harris, 2016), the virtual world of San Junipero is a recreation of the nineteen eighties which is visited by the elderly as a form of therapy. Significantly, the elderly and dying can also choose to 'pass over' to San Junipero which appears to be a form of digital uploading or copying where a version of that person 'moves' to San Junipero and inhabits their more youthful avatar for the foreseeable future. Unlike 'Be Right Back', 'San Junipero' is less concerned about how this technology might work, and is more ambivalent in terms of this being a positive or negative development. One of the two lead characters, it is revealed, has spent most of her life completely paralysed, but the San Junipero virtual world allows her to escape these physical confines both in later life and, at the episode's conclusion, in (physical) death as she uploads permanently. The final scenes of the episode juxtapose the virtual world of San Junipero with an enormous data processing facility which houses the digital environment, and its inhabitants, set against Belinda Carlisle's eighties classic song 'Heaven is a Place on Earth' (1987). The episode's conclusion is thus very deliberately open ended, begging questions of both how constructed San Junipero is as a form of afterlife, but also how culturally constructed all forms and understandings of heaven or the afterlife may be.

\section{LivesOn}

LivesOn is the brainchild of the marketing agency Lean Mean Fighting Machine in the UK (Coldwell, 2013). They timed the announcement of their service's launch to coincide with the first screening of 'Be Right Back', which gained them significant media attention, even if the service itself was not actually released at the time. With the tagline "When your heart stops beating, you'll keep tweeting", LivesOn asks users to allow proprietary algorithms to analyse a user's Twitter activity on a day to day basis, 'learning' who they are through the way they tweet. A separate Twitter account (only visible to the user) starts to estimate what the 'real' account will say, with the expectation that the longer it runs, the more accurate the service will be, and, the closer the tweets will match. The eventual goal is that the digital version can take over, having 'learnt' the voice of that user, Tweeting in the user's name, long after they've passed away. The digital version is placed in the hands of an executor who, ultimately, decides the fate of this reanimated social media spectre. Along with the timing and attention from 'Be Right Back', LivesOn seems designed to amplify the mistakes the episode warns viewers about. The service presumes social media traces can tell the whole (or enough) of the story of someone's life, and that their continued Twitter output offers some semblance of an ongoing existence (Leaver, 2013). However, and rather ironically, the LivesOn service itself now seems to be defunct, with no evidence of activity or development for several years.

\section{EterniMe}

Eterni.Me is another technology startup company that seeks to harvest people's social media history, and more, to create a digital amalgam of that person. In addition to everyday traces, the service asks users to document their most important memories and stories so they can be accessed after the user dies. Eterni.me's original promotional material explained that with their algorithm, these memories could be re-animated to the point, like 'Be Right Back', where users could 'Skype chat' with the dead (Meese, Nansen, Kohn, Arnold, \& Gibbs, 2015). Initial press stories in Wired and 
elsewhere focused on this aspect, describing the service as 'creepy' (Clark, 2014; Starr, 2014). Founder Marius Ursache, later lamented that the focus on this element overly influenced how people thought of the project. In an interview he commented, "It's not the point of Eterni.me-it's just the interface... The avatar acts as a librarian, helping users make sense of the stored information," (Parker, 2014). The algorithms and interface thus make the information animate enough to interact with, even if the company have become more restrained in how they describe the actions of this interface. As of July 2016, the website still makes some bold claims, though:

You could preserve your parents' memories forever? And you could keep their stories alive, for your children, grandchildren and for many generations to come? ... We want to preserve for eternity the memories, ideas, creations and stories of billions of people. Think of it like a library that has people instead of books, or an interactive history of the current and future generations. An invaluable treasure for humanity. ("Eterni.me - Virtual Immortality," 2016)

If the interface to interact "almost as if they were talking to you" after that person is deceased, then there is still the underlying presumption that the digital residues stored, sorted, analysed and algorithmically animated are, at the very least, an approximation of the deceased person.

\section{Learning To Be Me}

In Australian science fiction author Greg Egan's short story 'Learning to Be Me' (Egan, 1995) he describes a near-future world where people purportedly achieve a semblance of immortality through a 'Jewel' computer which is implanted in their brains at an early age and as they grow learns to replicate the brain's behaviour. Over time, the Jewel is thought to become a copy of the person in question, and eventually, before a certain age where the physical brain deteriorates, the organic brain is replaced with the Jewel. The Jewel is exceptionally robust, meaning the pattern of information that is the individual can persist for an indefinite period of time. In the society Egan describes, the Jewel is supposedly monitored immediately after it 'takes over' to ensure it is the person it's supposed to be. However, two-thirds through Egan's short story, the perspective shifts and the protagonist cannot move their body; after some confusion the reader discovers this is the perspective of the Jewel, not the organic mind it is supposed to the mimicking. The Jewel spends the remainder of the story terrified that after the organic brain is removed, normal testing will reveal the Jewel is not an exact copy, and it will be terminated. The climax of the story effectively, is that not only do the monitors not notice that the Jewel had diverged from the person it replicated, but the implication is that this often if not always happens. Jewels might house consciousness, sentience and intelligence, but they are definitively not 'the same' as the organic person they replace. 'Learning to Be Me' thus offers a stark warning that even if technology might one day house intelligence and even sentience, the odds of that life being 'the same' or replicating an organic human template is extremely low.

\section{Humai}

The third contemporary company working on digitally-facilitated resurrection, or immortality, is Humai who also seek to offer 'the same' life, but one without end, to their customers. Humai's core strength is robotics, and the company is working on creating entirely artificial bodies which can function as well as, if not better than, human bodies, and can function indefinitely. As well as a 
replacement robotic body, Humai also initiated Project Soul which was "an artificial replica that can communicate with family and friends after death". This replica was similar to the LivesOn and EnterniMe projects in that it was a digital reanimation of an individual (Gershgorn \& Fecht, 2015). The core difference, though, was that Project Soul was a stepping stone, with the real aim being to re-integrate the mind and body in human-looking robotic form. However, in 2016 Project Soul was put on hold, with the company's website now focusing on the robotic bodies as vessels for reanimated organic brains:

The challenges are significant: taking a dead brain and bringing it back to life; wiring up the brain so that it can control a silicon-based machine; and trying to replicate that vital thing that is you--your personality, your past experiences, your mind. We want to transplant your brain into an elegantly designed bionic body called Humai. ... As your brain matures, genetic engineering will combat the aging process. (Humai, 2016)

Significantly, Humai have shifted focus to building bodies and trying to preserve organic brains as best they can, only (slowly) replacing them with nanotechnology as the organic material becomes unrepairable. Their quest for robotic immortality provokes many questions, practical, political and ethical most of which have been explored in detail in the work of Greg Egan.

\section{Permutation City}

Greg Egan's fiction frequently explores the potential of digital life, both in the form of uploaded humans and informatic life which is indigenous to digital realms (Leaver, 2012). However, nowhere is the boundary between organic and digital life, and the question of whether an algorithmic afterlife is possible, explored more provocatively than in Permutation City (1994). Maria Deluca is one of the main protagonists of the novel, whose life is turned upside down when a hobby exploring synthetic digital biology unexpectedly sees her become part of a larger project which includes a 'seed' for indigenous digital lifeforms (something that provokes its own complex ethical questions, as discussed in Leaver, 2004). Maria's motivation for joining this project is very simple: her mother is terminally ill and Maria wants to pay for what treatment she can and, importantly, she wants her mother's brain to be scanned and a digital Copy created that can be activated in the event of her mother's physical death. However, when Maria reveals her plan to her mother, the discussion reveals some important and largely unanswerable questions of ontology. Francesca, Maria's mother, believes Copies are sentient, but not the same as the person copied: 'I do believe that Copies are intelligent. I just wouldn't say that they are - or they aren't - "the same person as" the person they were based on. There's no right or wrong answer to that; it's a question of semantics, not truth' (Egan, 1994, p. 77). To Maria's great frustration, Francesca chooses not to be scanned at all, as she perceives creating a Copy as 'something rich eccentrics do-the way they used to freeze their corpses' (Egan, 1994, p. 84). Creating a Copy is thus linked to cryogenics, the notion of freezing a recently deceased person at a very low temperature, presuming that eventually medical technology will be sufficiently advanced that they can be defrosted, reanimated and cured (Teitge, 1984). Creating Copies, like cryogenics, is thus also about the deep-seated human desire to escape death, although from Frankenstein onwards doing so via technology usually entail unforeseen problems. As with Egan's 'Learning to Be Me' short story, the question of how you tell if a digital version of a person is 'the same' as the organic template or not hangs over the entirety of Permutation City. 
The characters in Permutation City who are already Copies demonstrate the full spectrum of what digital existence might mean after organic death. Whilst the Copies are no longer legally people, some are determined to stay engaged with the material world, consuming news and information, and offering advice and guidance to their companies and families, living a digital approximation not dissimilar to their previous lives. The characters Peer and Kate, however, are part of a Copy political movement called 'Solipsist Nation' in which they denounce the need to stay connected with the outside or material world. At one point Peer rejects being human or wanting human rights, stating they are 'for people who want to play at being human. I know who I am. I am not human' (Egan, 1994, p. 63). Moreover, as a somewhat gruesome illustration of this point, Peer plunges his hand into his chest and pulls his heart out of his chest cavity; illustrating the artificiality of their 'biology', Peer's 'heart kept beating in his hand as if nothing had happened; the blood passed straight between the ragged ends of each broken artery, ignoring the "intervening distance"' (Egan, 1994, p. 63). While this demonstration shows how different biological and digital bodies can be, Kate nevertheless chides Peer for thinking this somehow showed their immortality or even guaranteed their persistence over time. Kate points out that their continued existence depends on computing companies being paid to run the virtual environment and complex algorithmic systems which 'are' Peer, Kate and the world they now inhabit. Indeed, Permutation City not only points out the ongoing need for expensive computing power, but ironically points to a digital divide between super-rich Copies, who are protected by extremely large and rich estates, compared to Copies who lack these funds who risk either not being 'run' at all, or experiencing cheaper and cheaper processing time and power. In a very literal demonstration of a class divide, to maximise the cheapest computing power, the poorest Copies experience time that is comparatively slower and slower than the material world. The poorer the Copy, the slower and more cheaply their world and thoughts are processed, and the slower their subjective experience of time is compared to the real, material world and the worlds of richer Copies.

The differences between digital Copies and organic people is most profoundly demonstrated when the Copies manipulate their own code (effectively, manipulating themselves). In Permutation City, each copy is legally a piece of software and must be governed by another software system called an exoself. The exoself allows any element of a Copy to be altered, and while this may have begun as a fine-tuning instrument, the uses in the novel are often more radical. Since all biology is now digital, Copies can 'feel' happy or sad or excited or drunk simply by issuing a command via their exoself. More dramatically, Copies can alter their own mental landscape, deleting old memories, creating new ones, altering their relative strength or vision or any other 'sense' in their digital environments. While entirely logical once the entity and the environment are information, these radical alterations highlight how different existence as a digital Copy could actually be. Simply having the ability to alter themselves in profound ways means that even if Copies might have been human-like initially, the way their selves and environments can be altered, seemingly without effort, illuminates a very different version of what 'being alive' might actually entail. While this exploration is exciting and philosophically interesting, it also explores the logical extremes of an algorithmic afterlife, illustrating forms of life which are notably different and decidedly alien compared to the confines of biological human life as it's currently understood. 


\section{Discussion and Conclusion}

Even though it is one of the most radical presumptions, and one that fuelled the posthuman fantasies of the late twentieth and early twenty-first centuries (Hayles, 1999), all of the digital afterlife start-ups examined in this chapter proceed from the position that human life can be transferred to, and replicated in, digital form. For LivesOn, Eterni.Me and Humai, there is a future, and profit to be made, in resurrecting people in digital forms. While this is, to some extent, a presumption shared by the designers of Artificial Intelligence and other scientific endeavours involving digital lifeforms (Kember, 2003; Leaver, 2012), it nevertheless joins these disciplines in devaluing the importance of materiality and biology as an inescapable context to human existence and personhood (Hayles, 1992).

Equally problematic is the presumption that the digital traces left behind on social media and on mobile devices are sufficient markers of a human life to allow an algorithmic system to base digital resurrection on just this material. Almost all contemporary research on social media, digital traces and identity points out the challenges that are inherent in the fact that representations on social media are always partial, incomplete, and often lose meaning as their initial contexts are lost (Marwick \& boyd, 2011; Papacharissi, 2010; Pearson, 2009). The partial picture of a person present on digital platforms, even for a prolific social media user, are, at best, incomplete, fragmented and unrepresentative of the gamut of a person's life. While social media has facilitated many new spaces and practices of mourning and commemoration (Leaver, 2013; Leaver \& Highfield, 2018; Meese et al., 2015; Nansen, Arnold, Gibbs, Kohn, \& Meese, 2016; Arnold, Gibbs, Kohn, Meese \& Nansen, 2018), the current limits of posthumous performance and residues are driven by the energy and effort of mourners and their uses of digital platforms. Social media, to date, provides spaces to remember and reminisce, not reanimate, the dead.

Like Victor Frankenstein in Mary Shelley's novel, the tech start-ups of today blindly treat digital resurrection as an outcome that justifies the means of achieving it. Yet SF as a genre continually offers new versions of the scientist and Frankenstein's monster as warning against poorly thought through technological advances. While extremely unlikely to succeed given the limits of contemporary technology, it is nevertheless urgent that society consider the philosophical and social implications of even a semblance of success. What social impact might the digital undead have, and what rights, if any, should these software amalgams be granted? While these are enormous and broad questions, the consideration to the topic already given in SF deserve closer attention today.

If digital reanimation and an algorithmic afterlife can be achieved, then the SF material examined in this chapter asks us to consider how we will recognise 'life' in this form, how we will distinguish genuine life from clever algorithms that mimic similar patterns, and where the line between simulated and authentic sentience lies. These big questions are deeply challenging since neither science nor philosophy comes near to giving a single answer or definition of material, biological life as it already exists. Moreover, as both Permutation City and 'Be Right Back' so provocatively ask, even if we accept digital systems as sentient in some form, how can we judge if the digital undead are 'the same' as the loved ones lost? The image of Ash in 'Be Right Back' living out a seemingly endless life in Martha's attic is one unsettling answer to this question. Finally, if digital people pass as-yet-undetermined tests for sentience-a Turning Test for the algorithmic afterlife-what rights should digitally resurrected people have? If they meet tests of sentience, should these entities be granted legal and moral rights? Will the digital undead have the right to be run indefinitely on the 
cloud, or will they 'die' again when their estates or loved ones can no longer afford to buy sufficient processing power and time? As the SF texts examined argue, these questions need answers before digital resurrection may be possible, not afterward.

As recently as August 2017, Wired magazine featured a cover story about a son who utilised basic chatbot technology to capture, integrate and reanimate his dying (now deceased) father's life and stories as a chatbot (Vlahos, 2017). Even though Shelley's Frankenstein is two hundred years old, in 2018 we are still fascinated and enthralled by the fantasy of electricity and science providing a path to reanimation and potential immortality. Many of the science fiction stories which have followed in Frankenstein's wake explore the complex social, ethical and political questions of technology being a conduit to a form of reincarnation and these stories are especially important today as digital resurrection becomes a sales pitch for new tech start-ups. Yet Frankenstein is a warning, not a business model. Contemporary start-ups need, at the very least, to come up with ethical, not just technical, approaches for dealing with the unlikely event of their own success.

\section{References}

Arnold, M., Gibbs, M., Kohn, T., Meese, J., \& Nansen, B. (2018). Death and Digital Media. London \& New York: Routledge.

Carlisle, B. (1987). Heaven Is a Place on Earth (Vol. Heaven on Earth).

Clark, L. (2014, February 5). This creepy Al will talk to loved ones when you die and preserve your digital footprint. Retrieved July 11, 2016, from http://www.wired.co.uk/article/eterni-lifeafter-death-ai

Coldwell, W. (2013, February 18). Why death is not the end of your social media life. The Guardian. Retrieved from https://www.theguardian.com/media/shortcuts/2013/feb/18/death-socialmedia-liveson-deadsocial

Egan, G. (1994). Permutation City. London: Millennium.

Egan, G. (1995). Learning to Be Me. In Axiomatic (pp. 201-220). London: Millennium.

Eterni.me - Virtual Immortality. (2016). Retrieved November 14, 2014, from http://eterni.me/index.html

Freedman, C. (2000). Critical Theory and Science Fiction. Hanover and London: Wesleyan University Press.

Gershgorn, D., \& Fecht, S. (2015, November 24). Humai Wants To Resurrect Humans Within 30 Years. Retrieved July 11, 2016, from http://www.popsci.com.au/science/medicine/humaiwants-to-resurrect-humans-within-30-years, 412164

Goffman, E. (1959). The Presentation of Self in Everyday Life. New York: Anchor Book.

Harris, O. (2013, February 11). Be Right Back. Black Mirror. UK: Channel Four.

Harris, O. (2016, October 21). San Junipero. Black Mirror. UK: Netflix.

Hayles, N. K. (1992). The Materiality of Informatics. Configurations, 1(1), 147-70.

Hayles, N. K. (1999). How We Became Posthuman. Chicago and London: University of Chicago Press.

Humai. (2016). Humai - Transcending Human Biology Through Robotics. Retrieved July 12, 2016, from http://humaitech.com/

Kember, S. (2003). Cyberfeminism and Artificial Life. London and New York: Routledge.

Leaver, T. (2004). Iatrogenic Permutations: From Digital Genesis to the Artificial Other. Comparative Literature Studies, 41(3), 424-435. https://doi.org/10.1353/cls.2004.0033

Leaver, T. (2012). Artificial Culture: Identity, Technology, and Bodies. New York and London: Routledge.

Leaver, T. (2013). The Social Media Contradiction: Data Mining and Digital Death. M/C Journal, 16(2). Retrieved from http://journal.mediaculture.org.au/index.php/mcjournal/article/viewArticle/625 
Leaver, T., \& Highfield, T. (2018). Visualising the ends of identity: pre-birth and post-death on Instagram. Information, Communication \& Society, 21(1), 30-45. https://doi.org/10.1080/1369118X.2016.1259343

LivesOn. (2013). LivesOn: Your Social Afterlife. Retrieved July 14, 2016, from http://liveson.org/connect.php

Marwick, A. E., \& boyd, danah. (2011). I tweet honestly, I tweet passionately: Twitter users, context collapse, and the imagined audience. New Media \& Society, 13(1), 114-133. https://doi.org/10.1177/1461444810365313

Meese, J., Nansen, B., Kohn, T., Arnold, M., \& Gibbs, M. (2015). Posthumous personhood and the affordances of digital media. Mortality, 20(4), 408-420. https://doi.org/10.1080/13576275.2015.1083724

Monnet, L. (2004). A-Life and the Uncanny in Final Fantasy: The Spirits Within. Science Fiction Studies, 13(1), 97-121.

Mori, M. (2012). The Uncanny Valley. IEEE Spectrum: Technology, Engineering, and Science News, 19(2), 98-100. https://doi.org/10.1109/MRA.2012.2192811

Nansen, B., Arnold, M., Gibbs, M., Kohn, T., \& Meese, J. (2016). Remembering Zyzz: Distributed Memories on Distributed Networks. In A. Hajek, C. Lohmeier, \& C. Pentzold (Eds.), Memory in a Mediated World: Remembrance and Reconstruction (1st ed. 2015 edition, pp. 261-280). Houndmills, Basingstoke, Hampshire ; New York: Palgrave Macmillan.

Papacharissi, Z. (Ed.). (2010). A Networked Self: Identity, Community, and Culture on Social Network Sites. Routledge.

Parker, L. (2014, April 4). How to Become Virtually Immortal. Retrieved July 11, 2016, from http://www.newyorker.com/tech/elements/how-to-become-virtually-immortal

Pearson, E. (2009). All the World Wide Web's a stage: The performance of identity in online social networks. First Monday, 14(3). Retrieved from http://firstmonday.org/htbin/cgiwrap/bin/ojs/index.php/fm/article/view/2162/2127

Ravetto-Biagioli, K. (2016). The digital uncanny and ghost effects. Screen, 57(1), 1-20. https://doi.org/10.1093/screen/hjw002

Shelley, M. (1823). Frankenstein: Or the Modern Prometheus. London; New York: Penguin Classics.

Starr, M. (2014, February 6). MIT's Eterni.me: Skype chat with the dead. Retrieved July 11, 2016, from http://www.cnet.com/au/news/mits-eterni-me-skype-chat-with-the-dead/

Teitge, J. S. (1984). Cryogenics: Producing a state of suspended reality. Death Education, 8(2-3), 169-177. https://doi.org/10.1080/07481188408252455

Vlahos, J. (2017, July 18). A Son's Race to Give His Dying Father Artificial Immortality. WIRED, (August). Retrieved from https://www.wired.com/story/a-sons-race-to-give-his-dyingfather-artificial-immortality/

Walter, T. (2015). Communication media and the dead: from the Stone Age to Facebook. Mortality, 20(3), 215-232. https://doi.org/10.1080/13576275.2014.993598 